\title{
Cisplatin-induced premature senescence with concomitant reduction of gap junctions in human fibroblasts
}

\author{
Wei ZHAO, Zhong Xiang LIN*, Zhi Qian ZHANG \\ Peking University School of Oncology, and Beijing Institute for Cancer Research, Beijing 100034, China.
}

\begin{abstract}
To examine the role of gap junctions in cell senescence, the changes of gap junctions in cisplatin-induced premature senescence of primary cultured fibroblasts were studied and compared with the replicative senescent human fibroblasts. Dye transfer assay for gap junction function and immunofluorescent staining for connexin 43 protein distribution were done respectively. Furthermore, cytofluorimetry and DAPI fluorescence staining were performed for cell cycle and apoptosis analysis. p53 gene expression level was detected with indirect immunofluorescence. We found that cisplatin $(10 \mathrm{mM})$ treatment could block cell growth cycle at G1 and induced premature senescence. The premature senescence changes included high frequency of apoptosis, elevation of p53 expression, loss of membranous gap junctions and reduction of dye-transfer capacity. These changes were comparable to the changes of replicative senescence of human fibroblasts. It was also concluded that cisplatin could induce premature senescence concomitant with inhibition of gap junctions in the fibroblasts. Loss of functional gap junctions from the cell membrane may account for the reduced intercellular communication in the premature senescent fibroblasts. The cell system we used may provide a model useful for the study of the gap junction thus promoting agents against premature senescence.
\end{abstract}

Keywords: cisplatin, premature senescence, gap junction, intercellular communication, connexin 43, fibroblasts.

\section{INTRODUCTION}

Most somatic cells lose the ability to proliferate after a finite number of cell divisions and end in a growth-arrest state known as replicative senescence. This is considered to be a genetically controlled process $[1,2]$. But young proliferating cells may arrest growth and develop some aspects of the senescence phenotype in response to sublethal doses of various compounds[3-5]. This has been considered to be the induction of premature senescence. Cisplatin has been known as an anti-neoplastic drug against tumor cells[6, 7]. Cisplatin-induced DNA damage was also reported in human fibroblast cells[7, 8]. However, it is not known if cisplatin will trigger a cascade of senescence responses in normal cells. Intercellular communication through gap junctions has long been known to play an important role in cell proliferation, as well as in cell differentiation[9, 10]. Several lines of evidence suggested that gap junctions are defective in replicative senescent human

*Corresponding author: Dr. Zhong Xiang LIN, Tel: 86-10-6617-9250 (Lab), or 86-10-6617-6447 (Inst. Office) Fax: 86-10-6617-5832,

E-mail: zhongxianglin@Yahoo.com cells $[11,12]$. In this work, changes of gap junctions were investigated in the study of the drug-induced premature senescence. It was found that cisplatin could induce premature senescence in young human fibroblasts, which exhibited phenotypes comparable to those seen in replicative senescent fibroblasts. The dye-transfer capacity that is representative of gap junctional cell-cell communication reduced in both drug-induced premature senescent cells and in untreated replicative- senescent cells. Immunofluorescent staining showed that connexin 43 (Cx43), the major gap junction protein of lung fibroblastic cells[13, 14 ], reduced dramatically in the membrane of both kinds of cells.

\section{MATERIALS AND METHODS}

\section{Cell culture}

Normal human lung fibroblasts were obtained from early subcultures of the primary human lung cells cultured in this laboratory [14]. Cells were cultured in RPMI 1640 medium (GIBCO) supplemented with $15 \%(\mathrm{v} / \mathrm{v})$ fetal bovine serum, 100 units of penicillin $/ \mathrm{ml}$, and $100 \mu \mathrm{g}$ of streptomycin $/ \mathrm{ml}$ at $37^{\circ} \mathrm{C}$ in a humidified $\mathrm{CO}_{2}(5 \%)$ incubator. Cells were grown on the bottom surface of glass flask to subconfluency (about 85-90\%) and then passaged every 3 days. The in vitro life span of these cells is expressed in passage number. Each 
passage represents approximately $2.5-3$ population doublings ( $\mathrm{PD}$, see following description). Cultures younger than passage $10(<\mathrm{G} 10)$ which showed high proliferative ability were designated young. Cultures around G20 showed a growth-delay and were designated intermediate. Cultures of G30-G37 had virtually ceased growth and thus could represent the replicative senescent cells. G37 showed no detectable growth for 3 weeks after plating. Ultimately all cells that reached the finite lifespan of 37 passages were in a state of growth arrest. Cells from every other passage were frozen and stored in liquid nitrogen for further investigation. Normal fibroblasts were also obtained from primary culture of late chicken embryo (11-day old) tissue. After exposure of chick fibroblasts to cisplatin, cell growth were arrested. Concomitantly the fibroblasts expressed the premature senescent phenotype which resembled that of human fibroblasts. Therefore these chick fibroblasts were used for comparative purposes in some experiments. Cisplatin (Sigma Chemical Co., $10 \mu M$ ) was added to the complete culture medium and incubated further as indicated in the figure legends.

\section{Cell population doubling time (Gt)}

Trypsinized cells were plated onto a 24-well culture plate (Falcon Co.). Five different cell concentrations (Ni) $\left(2 \times 10^{4} /\right.$ well, $1 \times 10^{4} /$ well, $5 \times 10^{3} /$ well, $2 \times 10^{3} /$ well, $1 \times 10^{3} /$ well) were inoculated into triplicate wells. Cell counts were made 1 day later. Following the sequence from high $\mathrm{Ni}$ to low $\mathrm{Ni}$, a triplicate of wells were trypsinized and counted each day. Cell number (Nf) was obtained by counting on a hemocytometer and from the average of the triplicate wells.

The population doubling (PD) was calculated following the formula:

$$
\mathrm{PD}=\operatorname{In}(\mathrm{Nf} / \mathrm{Ni}) / \text { In } 2
$$

In: natural logarithm[15]. Population doubling time (Gt) was calculated from the formula: $\mathrm{Gt}=\mathrm{t} / \mathrm{PD}$, t: the time length (hr) of the day after inoculation. Average Gt was obtained from the Gt of the counted days.

\section{Cell growth curve}

Fifteen wells were plated with $2 \times 10^{4}$ cells/well. Cells from each well of the triplicate were trypsinized and counted daily as described above, and the mean number of cells /well was obtained every day from the triplicate average.

\section{Cell mitotic activity}

The mitotic index (MI) was examined. Cells were fixed in $2 \%$ formaldehyde in PBS, extracted with $0.5 \%$ Triton X-100 ( Sigma Chemical Co.) in PBS for $30 \mathrm{~min}$, and then were stained with a DNA specific binding fluorescent dye DAPI (4, 6-diamidino-2phenylindole dihydrochloride; Polysciences, Warrington, PA). Mitotic figures were counted under an Olympus fluorescence reflective microscope, $40 \times$ lens. $\mathrm{MI}=$ mitotic figures $/ 1000$ nuclei. $\mathrm{N}=1000$.

\section{DNA fragmentation examination}

In DAPI stained cells, nuclei with fragmented DNA were conspicuously different from the normal nuclei[16] . Number of fragmented DNA /1000 nuclei was taken as the apoptotic index (AI). N $=1000$.

In vitro cell cycle analysis-cytofluorimetry (CFM)
Cells $\left(\sim 2 \times 10^{6}\right.$ cells) were harvested and centrifuged $(800 \mathrm{rpm})$ for $5 \mathrm{~min}$. $0.5 \mathrm{ml}$ PBS was added to resuspend the cells. Then $95 \%$ ethanol was added to a final volume of $2 \mathrm{ml}$, and was stored at $4^{\circ} \mathrm{C}$ overnight. The cell sample was centrifuged and washed twice with PBS, then was suspended and stained in $0.5 \mathrm{ml}$ PBS containing Propidium iodide (PI , $1 \mathrm{mg} / \mathrm{ml}$ ) for $30 \mathrm{~min}$ in the dark. Cell cycle analysis was performed on a Model Coolper XL cytofluorimeter and analyzed by a multicycle software. DNA content and the hypoploidy were also measured [17].

\section{Scrape loading and dye transfer (SLDT) technique}

To detect cell-cell communication via gap junctions, a fluorescent dye, Lucifer Yellow (Sigma) was used. This technique introduces macromolecules into cells by a transient perturbation of the cell membrane that does not affect cell viability. Lucifer Yellow does not diffuse through intact cell membranes, but its low molecular mass permits diffusion through patent gap junctions. Cells along the scraped line are loaded with dye and thus transfer dye to their neighboring cells in a few minutes through gap junctions. If gap junction function is inhibited, cells do not transfer dye. Only the loaded cells along the scraped line would show fluorescence. Rhodamine dextran $(\mathrm{Mr} \approx 10$, 000 ) is used as control, because it cannot diffuse through intact cell membranes or gap junctions. When added simultaneously, they can be used to verify that dye transfer occurs through intercellular gap junctions only. Several studies have demonstrated that such dye transfer is related to the morphological presence of gap junctions, radioactive metabolite transfer, and electrical coupling between cells $[18,19]$.

\section{Antibodies}

Connexin $43(\mathrm{Cx} 43)$ antibody (kindly provided by Dr. Bruce Nicholson, SUNY at Buffalo) is a poly-clonal against the synthesized $\mathrm{Cx} 43$ peptide containing the amino sequence 252-271[20]. Anti$\mathrm{Cx} 43$ antibody has no cross reaction with other connexin proteins. Monoclonal antibody against p53 (Clone BP53-12, Sigma) stains nuclei of apoptotic cells but it does not stain the normal nuclei.

\section{Immunofluorescence staining and microscopy}

For immunofluorescence microscopy, cells were rinsed with PBS and fixed with $2 \%$ formaldehyde in PBS for $3 \mathrm{~min}$ at room temperature. They were then permeablized with $0.5 \%$ Triton X-100 (Sigma Chemical Co.) in PBS for $30 \mathrm{~min}$. This PBS-Triton solution was also used for all subsequent antibody-washing steps. All primary antibodies were used at an appropriate dilution for $1 \mathrm{~h}$ at $37^{\circ} \mathrm{C}$ in humid chamber. Afterwards, stained samples were washed with washing solution for three times $10 \mathrm{~min}$ each. All secondary antibodies (Jackson ImmunoResearch Labo-ratories, West Grove, PA) were affinity-purified and tagged with rhodamine, or fluorescein (FITC) and used at a 1:100 dilution. The nuclear dye, DAPI was used at $2 \mu \mathrm{g} / \mathrm{ml}$ in $0.9 \%$ $\mathrm{NaCl}$ for 5 min. Specimens were mounted in $60 \%$ glycerol in PBS containing 2.5\% DABCO (1,4-diazabicyclo $(2,2,2)$ octane; Sigma Chemical Co.). Cell samples were examined with epifluorescence microscope (Olympus), using filter sets that are selective for rhodamine, fluorescien, or DAPI. Color photographs were taken by an equipped digital camera and printed through Photoshop soft disc to a Fujifilm printer 3500. Black and white micrographs were taken 


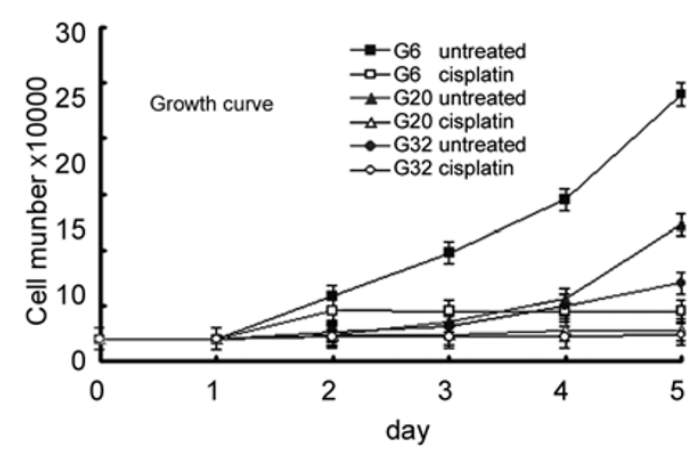

Fig 1. Growth curves of human lung cells. $2 \times 10^{4}$ cells per well were plated in 24-well culture plate. Cells were trypsinized every day from the next day and counted by using a Hemocytometer. Average of cell countings from the triplicate was obtained and SD value was calculated statistically. In the cisplatin treatment, cisplatin $(10 \mu M)$ was added to the culture media by the $6 \mathrm{~h}$ after plating when cells were attached to the substrate.

Tab 1. Comparison between young and senescent human fibroblast cells.

\begin{tabular}{|c|c|c|c|c|}
\hline & G6 & G20 & G32 & Cisplatin $^{@}$ \\
\hline $\mathrm{Gt}(\mathrm{h})^{*}$ & $23 \pm 2.345$ & $47 \pm 4.10$ & \multicolumn{2}{|c|}{$59 \pm 4.266 \Delta 175 \pm 10.47 \square$} \\
\hline MI & 19 & 12 & $0^{* *}$ & $0^{* *}$ \\
\hline $\mathrm{AI}^{*}$ & $0^{* *}$ & $40 \pm 2.01$ & $112 \pm 56$ & $330 \pm 16.5$ \\
\hline $\mathrm{P}^{2}+^{*}$ & $0^{* *}$ & $60 \pm 3.15$ & $129 \pm 45$ & $780 \pm 38.5$ \\
\hline Cx43 & membrane & membrane & reduced & disappear \\
\hline Dye Tra & *** $4+$ & $3+$ & $2+$ & low \\
\hline
\end{tabular}

@: Cisplatin $(10 \mu M, 24 \mathrm{~h})$ treated G 20 cultures; *: Results are presented as the mean \pm SEM. Statistical significance was determined using independent Student's $t$ test for paired samples by SPSS. $\Delta \mathrm{G} 32$ vs. G6, P<0.01. G20-cisplatin vs. G20-control, $\mathrm{P}<0.01$; **: total counting 1000 nuclei, repeatable in 3 separate cultures; ***: Dye transfer through over 4 gradients of the adjacent cells scored $4+; 3$ or more gradients scored $3+; 2$ or more gradients scored 2+. Less than 2 gradients scored low. Abbreviations: MI: mitotic index(\%o). AI: apoptotic index(\%o). Gt: population doubling time.

with either 40x or 100x 1.3 oil immersion objectives using 400 ASA film (T-max, black and white; Eastman Kodak Co., Rochester, NY).

\section{RESULTS}

\section{Cisplatin arrested cell growth}

As shown in the cell growth curve, cells stopped growing as early as $24 \mathrm{~h}$ exposure to $10 \mu M$ cisplatin. Different passages of cisplatin-treated cells showed an inhibition of the growth curve comparable to the untreated growth arrested replicative senescent cells. In contrast to both the cisplatin treated- and the senescent cells, the untreated young cultures showed high proliferative ability while the middle-aged cultures showed a growth-delay (Fig 1).
A

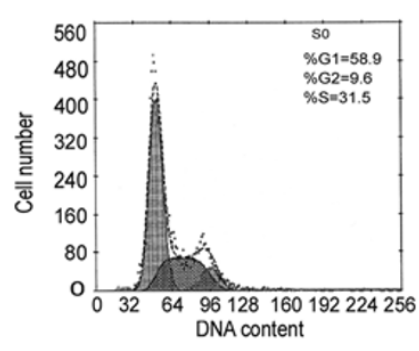

B

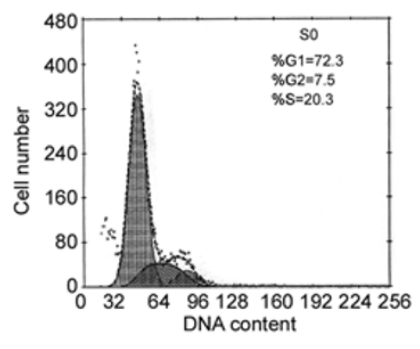

Fig 2. Cell cycle analysis of propidium iodide stained human fibroblasts. Propidium iodide staining was performed as described in Materials and Methods. The samples were analyzed by flow cytometry. (A) Cell cycle analysis of untreated normal young G8 cells. (B) Cell cycle analysis of G8 cells after exposure to $10 \mu \mathrm{M}$ cisplatin for $48 \mathrm{~h}$.

The cisplatin effect on cell growth was also reflected by the delayed population doubling time (Gt, Tab 1). For the cisplatin treated cells, their Gt was $175 \pm 10.4 \mathrm{~h}$. While there was a gradual increase of Gt during the process of aging in normal untreated human fibroblasts; eg. Gt of 23 $\pm 2.3 \mathrm{~h}$ in young cells; Gt of $47 \pm 4.1 \mathrm{~h}$ in middle-aged; Gt of $59 \pm 4.2 \mathrm{~h}$ in senescent cells, and Gt of the cisplatin treated cells reached the longest (Tab 1).

\section{Cisplatin inhibited mitotic activity}

The frequency of mitotic figures in 1000 randomly counted DAPI stained nuclei was called mitotic index (MI). MI was relatively high in young cells $(\mathrm{G} 6, \mathrm{MI}=19)$ and it decreased in intermediate-aged cells $(\mathrm{G} 20, \mathrm{MI}=12)$. The MI was reduced to 0 in both replicative senescent fibroblasts and in cells exposed to cisplatin (Tab 1). The cisplatin effect on MI was observed not only in human fibroblasts but also in chicken fibroblasts (data not shown).

\section{Cell-cycle blockade of cisplatin-treated fibroblasts -- CFM analysis}

DNA content analysis showed typical diploid cycle phases in untreated control cells of young G8. These cells were in a constant replication condition, about $1 / 3$ of the population were in DNA replication phase $\mathrm{S}(\% \mathrm{~S}=31.5)$. After $48 \mathrm{~h}$ exposure to cisplatin, G1 $(\% \mathrm{G} 1=72.3)$ increased $\sim 13.4 \%$ and $\mathrm{S}(\% \mathrm{~S}=20.3)$ decreased $11.2 \%$. Cisplatin treatment blocked the cell cycle at the G1 and inhibited cells from entry into S phase. (Fig 2).

\section{High frequency of nuclear DNA fragmentation in cisplatin treated cells}

Nuclear DNA fragmentation of apoptotic cells was identified morphologically by nuclear dye DAPI fluorescent 

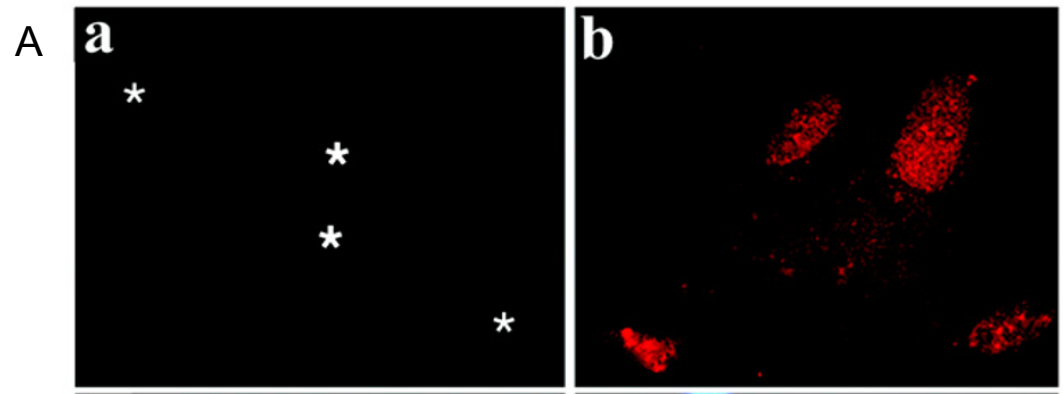

Fig 3 (A). Immunofluorescent triple stained micrographs. Column a-a', normal young G8 human fibroblasts. Stars mark the nuclei area. Column b-b', cisplatin $10 \mu \mathrm{M}, 24 \mathrm{~h}$ treated G8 cells. Stars mark the nuclei area. a \& b, p53 immunofluorescence stained nuclei in rhodamine channel. a'\& b', DAPI stained nuclei. a' \& b', Cx43 immunofluorescence stained gap junction protein in FITC channel. Bar $=10 \mu \mathrm{m}$. (B), phase contrast micrographs. a, normal young
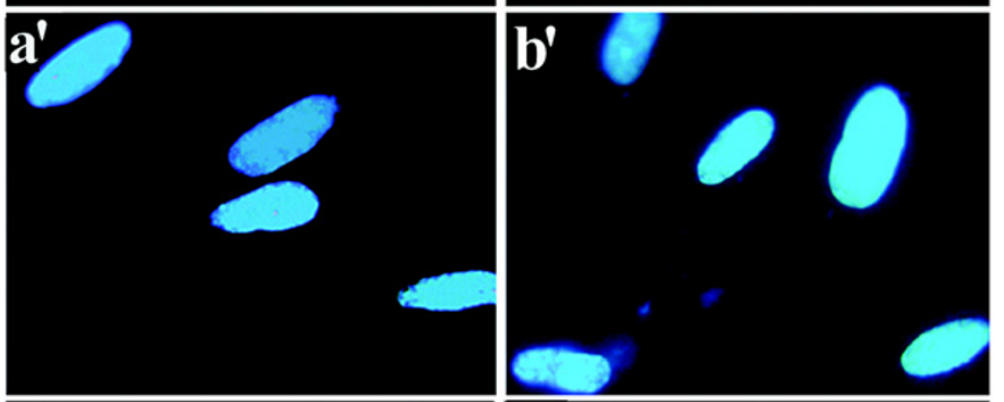
fibroblasts. b, cisplatin treated $24 \mathrm{~h}$ fibroblasts. c, cisplatin treated $48 \mathrm{~h}$ fibroblasts.

$\operatorname{Bar}=50 \mu \mathrm{m}$.
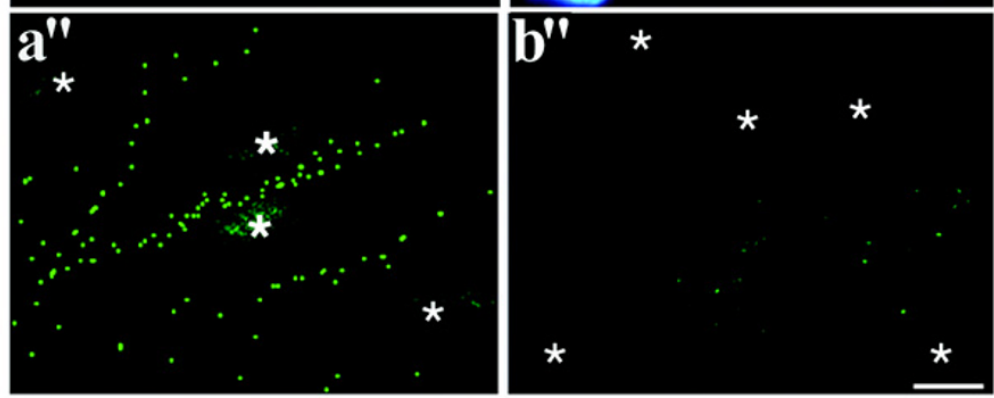

B

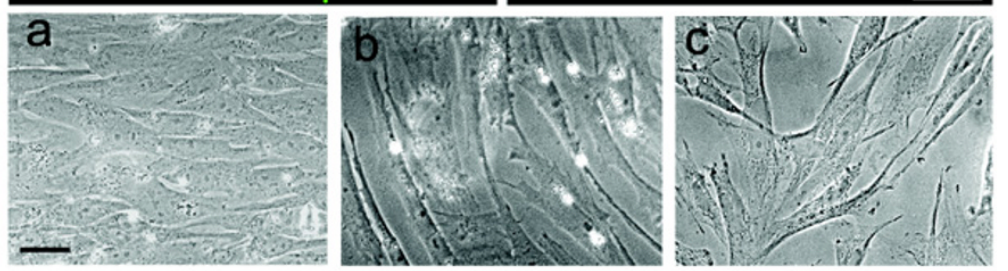

staining pattern of chromatin condensation . The number of the DAPI stained DNA fragmentation in 1000 counted nuclei is called Apoptotic Index (AI) in the following description. According to our studies, AI was not found in normal untreated young cells (G6-G8, AI =0). Middleagged cells showed a modest number of $\mathrm{AI}(\mathrm{G} 20, \mathrm{AI}=40 \pm 2$. $01)$, but after exposure to cisplatin their DNA fragmentation frequency reached the higest $(\mathrm{AI}=330 \pm 16.5)$, which was consistent with the increase of $\mathrm{AI}$ in untreated replicative senescent cells (G32, AI=112 \pm 56$)$ (Tab 1).

\section{Increased p53 immunofluorescence in cisplatin-treated cells}

The monoclonal anti-p53 antibody stained positive only in part of the cell samples. Labelled with rhodamine, the p53 immunofluorescence displayed an amorphous red dif- fusion feature that distributed exclusively in nuclear area. Cytoplasmic staining of p53 was never observed in the samples detected. The p53 positive frequency varied in different samples. As shown in Tab 3 and Fig 3, the p53 staining was negative in the nuclei of untreated normal young cells but became positive in the nuclei of aged cells. The ratio of p53-positive nuclei in 1000 counted nuclei was obtained. The ratio rose along with aging of the untreated fibroblasts, and reached to the highest of $129 \pm 45$ in the untreated replicative senescent fibroblasts. The ratio of p53-positive nuclei can reflect early changes of p53 expression level when the emerged smaller number of p53 positive nuclei is hard to detect in analysis from an average sample of a mixed cell population. In the cisplatin treated fibroblasts we observed a dramatic increase of the p53 expression: the p53-positive nuclei ratio was as high as 


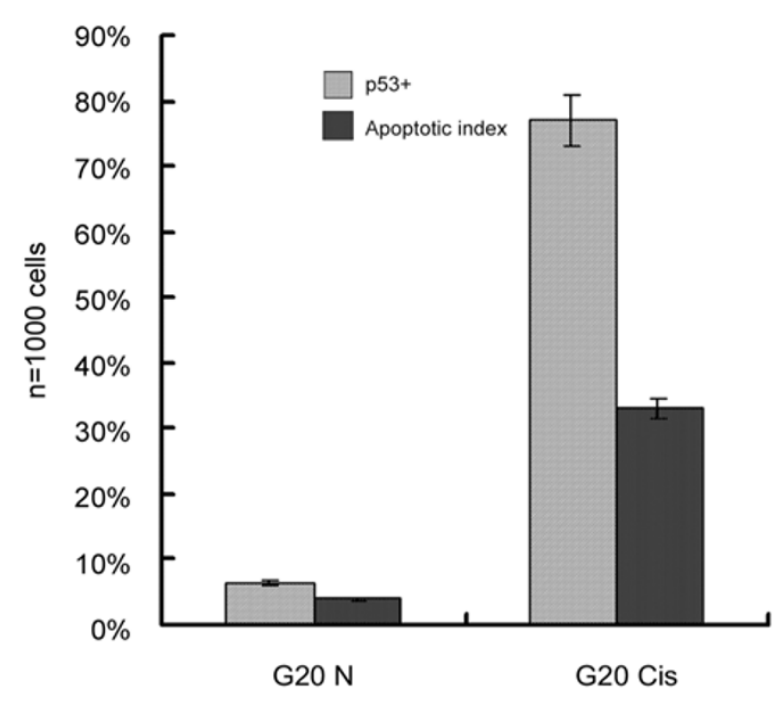

Fig 4. Relative levels of p53 positive nuclei to DAPI/fragmented nuclei in passage 20 normal fibroblast cells (G20 N) and cisplatin(10 $\mathrm{uM}, 24 \mathrm{~h}$ ) treated passage 20 cells (G20 Cis) in double staining of p53 and DAPI fluorescence.

$780 \pm 38.5$ (Tab 1) (Fig 3). Among the p53-positive stained nuclei, the immunofluorescence intensity differed from weak to intense. In triple-fluorescent stained samples it was noted that the frequency of p53-positive nuclei was higher than that of DNA fragmented nuclei. Although some of the p53-positive nuclei did not exhibit DNA/DAPI fragmentation (Fig 3), the overall frequency of p53-positive nuclei was in parallel with the increasing tendency of the DNA fragmentation in the cell samples of cisplatin-induced premature senescence as well as in the progress of cell replicative senescence (Tab 1) (Fig 4).

\section{Inhibition of introcellular communication by cisplatin}

Normal untreated young fibroblast cells (G8) were well coupled by gap junctions. Luciferous Yellow dye was transferred from the loaded cells at the scraped line to the adjacent cells over 4-5 gradients (Fig 5a, a'). Middle-aged (G20) cells decreased in their dye transfer capacity. Dye was transferred to the adjacent cells only through 2 or 3 gradients (Fig 5b, b'). G8 or G20 cells after exposure to cisplatin $(10 \mu M, 24 \mathrm{~h})$ were uncoupled to a certain degree, as shown in their reduced capacity for dye transfer, through 2 or less layers of the adjacent cells only (Fig 5c, c') (Tab 1). These results indicated that gap junction intercellular communication function declined during the development of the replicative senescence of human fibroblasts. Cisplatin treatment induces premature senescence concomitant with the inhibition of gap junction communication.

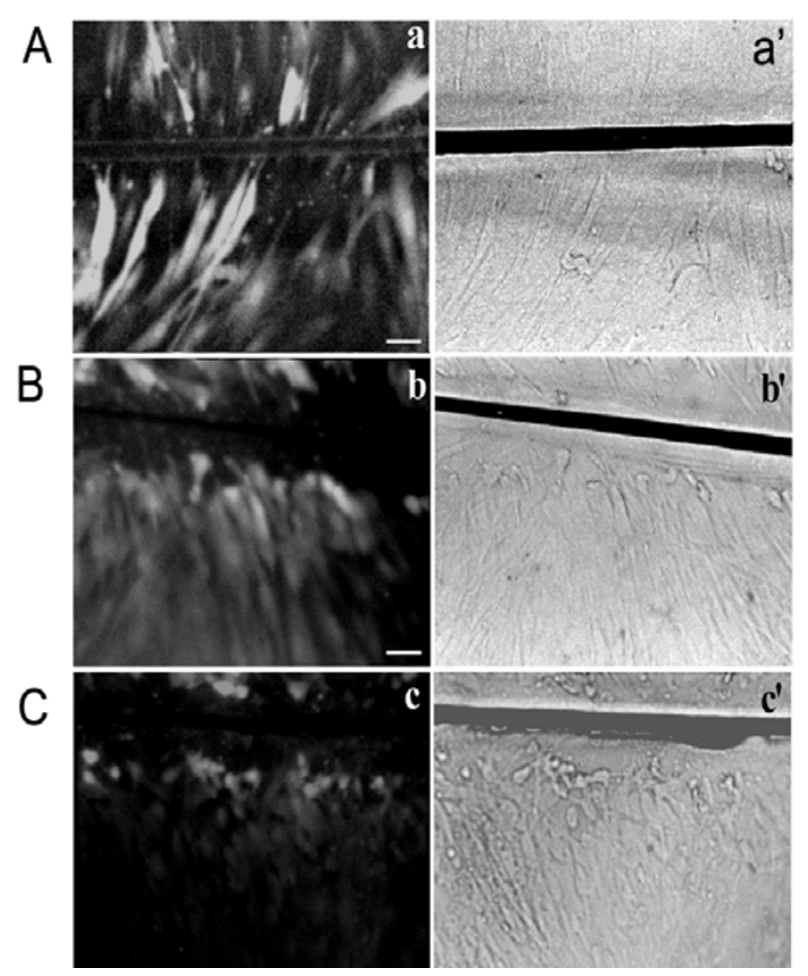

Fig 5 Lucifer Yellow fluorescence dye transfer micrographs. Monolayer cell cultures were loaded with Lucifer Yellow as described in Matirials and Methods. Dye transfer form scraped line to adjacent cells were recorded. (A), Young untreated G8 cells. (B), untreated G20 cells. (C), cisplatin (10 $\mu M, 24$ h) treated G8 cells. a, b \& c are fluorecent micrographs of dye transfer result. a', b' \& c' are the respective light field micrographs. bar $=50 \mu \mathrm{m}$.

\section{Cx43 immnuofluorescence in cisplatin-induced premature senescent cells}

Cells were triple-stained with (1) Cx43 poly-clonal antibody; (2) Monoclonal antibody (Mab) against p53; and (3) DAPI nuclear dye. FITC-conjugated goat-anti-rabbit IgG, and rhodamine-conjugated goat-anti-mouse IgG were used as the secondary antibodies. The combination of the three colors of FITC-, Rhodamine- immunofluorescence with DAPI blue fluorescence is a useful method in studying the correlation between gap junction expression and the different ages of the cells in a mixed population. Cx43FITC immunofluorescence stained dotted lines outlined the cell-cell contact membrane border of both human and chicken normal fibroblasts. The Cx43 immunofluorescent dots at the cell membrane very likely labelled the membrane gap junctions (Fig 3a"). After treatment with cisplatin, Cx43 immunofluorescent staining reduced obviously or entirely disappeared from the cell membrane. Although dispersed Cx43 immunofluorescent dots in the cytoplasm were observed in some cells, the overall $\mathrm{Cx} 43$ staining was much lower than in untreated normal fibroblasts (Fig. 3 , compare b" with a"). The loss of membrane Cx43 im- 
munofluorescence in the cisplatin-treated cells resembled the $\mathrm{Cx} 43$ staining observed in the untreated late passaged human replicative senescent fibroblasts (photo not shown).

\section{Morphological changes of the cisplatin-induced premature senescent cells}

Under the phase contrast microscope, normal fibroblasts showed full cell body with thick and opaque cytoplasm and cell processes, but in rare cases, filopodia. The cisplatintreated human and chick fibroblasts showed morphological changes that were very similar to those in the untreated replicative senescent fibroblasts: they developed a large, flattened cell-shape and extended filopodia. Granules and vacuoles in the cytoplasm increased overtime (Fig $3 \mathrm{c}, \mathrm{d}$, and e).

\section{DISCUSSION}

This work was designed to confirm the importance of gap junction cell-cell communication in cisplatin induced premature senescence. Cisplatin is a member of DNAdamaging agents used in the treatment of malignant tumors. Some cancer cells can be killed by cisplatin via a p53independent route with some similarities to replicative senescence[6]. The cisplatin-treated WI38 fibroblasts and fibroblasts of other species have been used as controls for cytotoxicity in the studies of DNA repair and the cisplatin resistance $[7,8]$. The present work demonstrated for the first time that exposure of human fibroblasts to cisplatin induced premature senescent changes similar to those seen in the replicative senescent fibroblastic cells. In normal fibroblasts the cisplatin treatment arrested cell growth at G1 phase of the cell cycle as well as up-regulated p53 expression. The p53 gene has been known as a negative regulator of growth in mammalian cells. Under normal conditions p53 levels are maintained at a low state by the virtue of the extremely short-half-life of the polypeptide. This may explain why p53 protein immunofluorescence was undetectable in the normal young cells used in this work (Fig 3, a)[21]. The increased p53 expression detected by immunofluorescent staining in the nuclei in senescent cells was consistent with the analytical results reported in the drug-induced premature senescence and in the replicative senescent diploid fibroblasts[4, 22, 23]. After exposure to cisplatin, unlike in some cancer cells[6], the changes of normal human fibroblast cells included elevation of p53 expression, G1 arrest and apoptosis. These are very likely to be the correlated events that developed in the cisplatin-induction of premature senescence. In fact, there was evidence that activation of p53 may cause cell cycle arrest at the G1 phase or lead to apoptosis of normal fibroblasts[23]. It is noteworthy that the response of the cultures to cisplatin was independent of their passage lev- els (Fig 1, Tab 1). Therefore, these cells establish a useful system for studying the mechanisms involved in the regulation of cell premature senescence.

Gap junctions of intercellular communication function in the exchange of molecules of less than $1200 \mathrm{Da}$, including secondary messengers, nutrients, and metabolites between adjacent cells. These molecules may carry signals of proliferation, differentiation and death. Relatively less is known about how gap junctions are involved in the control of cell death. Reduced gap junction cell-cell communication and down-regulated expression of $\mathrm{Cx} 43$ were reported in the senescent endothelial cells [12] and in the senescent human fibroblasts[11]. The current results support the previous findings. In addition, this paper demonstrates that: (1) There is a gradual reduction of gap junctions as the cells are getting age; comparing with young cells, the middle-aged show less gap junction activity while in senescent cells the gap junction activity is the lowest (Fig 5); (2) A similar reduction in gap junctions is also seen in human fibroblasts undergoing a cisplatin-induced premature senescent changes; (3) Cisplatin-treatment of chicken fibroblasts also induces some premature senescent phenotypes as well as the loss of the membranous $\mathrm{Cx} 43$. Promising roles of gap junctions in the controling of cell death have been suggested by reports from others, though different kinds of experiments have led to different conclusions[24-27]. It is necessary to design further experiments to resolve this mechenism.

\section{ACKNOWLEDGEMENTS}

This work was supported by grants from (1) The National Key Program for Basic Research, Project No. G2000057002; (2) National Natural Science Foudation of China, Project No. 30270685. The authors are indebted to Dr. S. Holtzer (University of Pennsylvania,USA ), Dr. JE Trosko (Michigan State University, USA) and Dr. C. C. G. Naus (University of British Columbia, Vancouver, $\mathrm{BC}$, Canada) for their critical review and reference suggestion.

\section{Received, April 28, 2003}

Revised, Oct 15, 2003

Accepted, Oct 24, 2003

\section{REFERENCES}

1 Hayflick L, The limited in vitro lifetime of human diploid cell strains. Exp Cell Res 1965; 37:614-36.

2 Smith JR, Pereira-Smith OM, Replicative senescence implications for in vivo aging and tumor suppression. Science 1996; 273:63-7.

3 Yeo EJ, Hwang YC, Kang CM, et al. Senescence-like changes induced by hydroxyurea in human diploid fibroblasts. Exp Gerontol 2000; 35:553-71.

4 Chen QM, Bartholomew JC, Campisi J, et al. Molecular analy- 
sis of $\mathrm{H}_{2} \mathrm{O}_{2}$-induced senescent-like growth arrest in normal human fibroblasts: $\mathrm{p} 53$ and $\mathrm{Rb}$ control $\mathrm{G} 1$ arrest but not cell replication. Biochem J 1998; 332:43-50.

5 Saretzki G, Feng J, Zglinicki T, et al. Similar gene expression pattern in senescent and hyperoxic-treated fibroblasts. J. Gerontol. Series A- Biol Sci \& Med Sci 1998; 53(6):B438-42.

6 Wang X, Liu Y, Chow LS, et al. Cisplatin-induced p53-independent growth arrest and cell death in cancer cells. Intl J Oncol 1999; 15:1097-102.

7 Meenakshi J, Nupama A, Goswami SK, Datta K, Constitutive expression of hyluronan binding protein 1 (HABP1/p32/gC1qR) in normal fibroblast cells perturbs its growth characters and induces apoptosis. BBRC 2003; 300(3):686-93.

8 Chang LC, Sheu HM, Huang YS, Tsai TR, Kuo KW, A novel function of emodin: enhancement of the nucleotide excision repair of UV- and cisplatin-induced DNA damage in human cells. Biochemical Pharmacology 1999; 58(1):49-57.

9 Naus CG, Gap junctions and tumour progression. Can J Physiol Pharmacol 2002; 80:136-41.

10 Wilson MR, Close TW, Trosko JE, Cell population dynamics (apoptosis, mitosis, and cell-cell communication) during disruption of homeostasis. Exp Cell Res 2000; 254:257-68.

11 Statuto M, Bianchi C, Perego R, Monte UD, Drop of connexin 43 in replicative senescence of human fibroblasts HEL-299 as a possible biomarker of senescence. Exp Gerontol 2002; 37:111320.

12 Xie HQ, Hu VW, Modulation of gap junctions in senescent endothelial cells. Exp Cell Res 1994; 214 (1):172-6.

13 Zhang ZQ, LIN ZX, Lu YY, Meng SN, Han YL, Expression of gap junction protein CX43 in cultured normal human embryonic lung cells and lung carcinoma cells. Acta Biophysica Sinica 1994; 10(3):411-6.

14 Zhang WJ, Zhang ZQ, Lin ZX, et al. Correlation between expression of cadherin and gap junctional communication in human lung carcinoma cells. Science in CHINA (series C) 1998; 41(4): 419-25.

15 Chang CC, Ruth E, Gibson-D A, et al. Growth-promoting effect of 12-O-tetradecanoylphorbol-13-acetate on cultured normal human fetal kidney epithelial cells. Cancer Res 1986; 46:6360-3.

16 Tepper CG, Seldin MF, Mudryj M, Fas-mediated apoptosis of proliferating, transiently growth-arrested, and senescent normal human fibroblasts. Exp Cell Res 2000; 260:9-19.
17 Storz P, Döppler H, Horn-Müller J, et al. TNF down-regulation of receptor tyrosine kinase-dependent mitogenic signal pathways as an important step in cytostasis induction and commitment to apoptosis of Kym-1 rhabdomyosarcoma cells. Cell Death and Differentiation 2000; 7:955-65.

18 EL-Fouly MH, Trosko JE, Chang CC, Scrape-loading and dye transfer: A rapid and simple technique to study gap junctional intercellular communication. Exp Cell Res 1987; 168:422-30.

19 Trosko JE, Chang CC, Wilson MR, et al, Gap junctions and the regulation of cellular functions of stem cells during development and differentiation. Methods 2000; 20:245-264.

20 Lin ZX, Zhang ZQ, Yu KR, et al. Increased junctional communication and forced expression of connexin 43 retards cell growth and enhances myogenic differentiation in rhabdomyosarcoma cells. Progress in Cell Research 1995; Vol. 4, pp. 31-35. edts. Y. Kanno, et al., Elsevier Science B.V. press.

21 Lakin ND, Jackson SP, Regulation of p53 in response to DNA damage. Oncogene 1999; 18:7644-55.

22 Kuliu KS, Lehman JM, Increased p53 protein associated with aging in human diploid fibroblasts. Exp Cell Res 1995; 217:33645.

$23 \mathrm{Kim} \mathrm{H}$, You S,Farris J, et al. Expression profiles of p53-, p16 ${ }^{\mathrm{INK} 4 \mathrm{a}}$, and telomere-regulating genes in replicative senescent primary human, mouse, and chicken fibroblast cells. Exp Cell Res 2002; 272:199-208.

24 Watanable H, Tonosaki A, Gap junction in the apoptosis: TEM observation of membrana-granulosa cells of mouse ovarian follicle. in "Progress in Cell Research" 1995; Vol. 4, pp37-40. Elsevier BV. Edts: Kanno Y. et al., Elsevier Science B.V. press

25 Yasui K, Kada K, Hojo M, et al,. Cell-to-cell interaction prevents cell death in cultured neonatal rat ventricular myocytes. Cardiovascular Research 2000; 48:68-76.

26 Sai K, Kang KS, Hirose A, et al., Inhibition of apoptosis by pentachlorophenol in v-myc-transfected rat liver epithelial cells: relation to down-regulation of gap junctional intercellular communication. Cancer Letters 2001; 173(2):163-74.

27 Krutovskikh VA, Piccoli C, Yamasaki H, et al. Gap junction intercellular communication propagates cell death in cancerous cells. Oncogene 2002; 21 (13):1989 -99. 